\title{
Embracing uncertainty: A discursive approach to understanding pathways for climate adaptation in Senegal
}

\author{
Sonja Ayeb-Karlsson ${ }^{1,2}$ (D) $\cdot$ Gino Fox ${ }^{3} \cdot$ Dominic Kniveton $^{3}$
}

Received: 19 January 2018 / Accepted: 25 March 2019 /Published online: 17 April 2019

(C) The Author(s) 2019

\begin{abstract}
Climate change threatens to increase the frequency and intensity of droughts and floods. There are large uncertainties related to unknowns around the future and society's responses to these threats. 'Uncertainty' as other words with the prefix 'un' (unknown, untold, unrest) often has negative connotations. Yet, uncertainty is manifested in virtually everything we do. To many in science, uncertainty is akin to error that should be minimised, a lack of knowledge that needs to be rectified. We argue that uncertainty rather should be embraced as a starting point for discussing pathways to climate adaptation. Here we follow a definition of 'pathways to adaptation' as representing a set of proactive changes in the present that move people from a climatically unsafe place, to positions of safety (self-defined as representing freedom from harm or adverse effect). This article applies an interdiscursive analytical approach where (un)certainty and (un)safety are used to deepen the understanding around the positions of people in Senegal, and their livelihoods, with respect to climate hazards. We examine the discursive socio-cultural values active in the climate adaptive space. Our findings show that people's adaptive decisions often were not based on climate information, but on discursive values and emotions that guided them in the direction of responses that felt right. We conclude that acknowledging different understandings and perceptions of uncertainty, and the goal of achieving safety, allows issues of power to be discussed. We contend that this process helps illuminate how to navigate pathways of adaptation to the impacts of climate variability and change.
\end{abstract}

Keywords Climate change $\cdot$ Discourse $\cdot$ Family therapy $\cdot$ Safe uncertainty $\cdot$ Senegal $\cdot$ Socio-cultural perceptions

\section{Introduction}

Conversations around how to adapt to climate variability and change often refer to different understandings of current climate conditions and future climate change. One widely published and well-referenced source of knowledge on climate

Sonja Ayeb-Karlsson

S.Ayeb-Karlsson@sussex.ac.uk; ayeb-karlsson@ehs.unu.edu

Gino Fox

G.Fox@sussex.ac.uk

Dominic Kniveton

D.R.Kniveton@sussex.ac.uk

1 BSMS, University of Sussex, Room 308, Arts Building C, Arts Road, Falmer, BN1 9SJ Brighton, UK

2 United Nations University - Institute for Environment and Human Security (UNU-EHS), Bonn, Germany

3 School of Global Studies, Department of Geography, University of Sussex, BN1 9QJ Brighton, UK change comes from the Intergovernmental Panel on Climate Change (IPCC). Established in 1988, the IPCC produces regular assessments of the scientific basis of climate change, its impacts and future risks. According to the IPCC, these assessments provide policy-makers with the basis for choosing different options for adaptation and mitigation.

The Intergovernmental Panel on Climate Change states that it has high confidence that the changing climate will continue to increase the climate risks of heatwaves, droughts and floods (IPCC 2014). Here, the IPCC refers to 'confidence' as relating to 'a synthesis of the evaluation of evidence and agreement' (IPCC 2014: 6), per the author teams of the IPCC. While risk is taken as ' $[t]$ he potential for consequences where something of value is at stake and where the outcome is uncertain, recognizing the diversity of values' (IPCC 2014: 6). Clearly, the IPCC warnings of increased risks from the impacts of anthropogenic climate change are relevant to a wide range of stakeholders from policy-makers to decision-takers and those impacted by both climate changes and the policies to address them. In aiming to provide a scientific basis to develop 
climate-related policies for governments at all levels, the IPCC is broadly following a 'speaking truth to power' framing of science, attempting to act as an independent and objective provider of knowledge to policy-makers (Hulme 2010, 2011; Eriksen et al. 2015; Baldwin 2016). Without going into an evaluation of the validity of such a role, the IPCC process involves the conceptualization and communication of the uncertainty associated with current climate knowledge. In turn, in a policy world, the IPCC's discourse ${ }^{1}$ around uncertainty and confidence frames the range of options explored and emphasis given to them in the resultant decision-making.

While the issue of uncertainty in science has been widely examined, it is only relatively recently that decision-making under uncertainty in the arena of climate adaptation has become popularised within academic circles as a subject of research. A number of approaches to understanding and supporting decision-making under uncertainty have been proposed, including: processual analysis, applied behaviour analysis and organizational behaviour management, foresight, adaptation pathways, theories of collective action, multiple streams framework, decision scaling, structured decisionmaking, robust decision support, and scenario planning (see Taylor et al. 2017). While these approaches mainly focus on the decision-making process, less attention has been placed on how climate knowledge and its uncertainties are framed from the perspective of decision-makers. These subjectively defined understandings of climate variability and change, often in terms of their impact on current livelihoods, vary with individual values, perspectives, worldviews and beliefs. It is the intention of this article to present a framework, to be used with decision-makers, and takers, and scientists, to help open up a discussion around climate change and pathways to adaptation by acknowledging these different framings. While doing so, the article introduces the concepts of (un)safe (un)certainty ${ }^{2}$ to frame this discussion. Pathways to adaptation approaches have been discussed by a number of authors (e.g. Haasnoot et al. 2013; Wilson 2014; Wise et al. 2014; Fischer 2018). In particular, Fischer (2018: 237) states: 'The notion of pathways provides a nuanced way to consider adaptation in the context [of] past conditions that have shaped vulnerability, specifically as a thread within a wider process of societal transition through interacting cultural, political, economic, and environmental change (Haasnoot et al. 2013; Wilson 2014; Wise et al. 2014)'. In this way, pathways are not seen as static, but evolving with continued learning and pluralism in response to

\footnotetext{
${ }^{1}$ In this article, we define discourse as 'collectively shared domains of statements'. As discourses can interact, complement or compete with one another, we aim to broaden the linguistic analysis beyond one collective narrative, attitude or perception (see Foucault 1981 and Fairclough 2003).

${ }^{2}$ In this article, we define safe uncertainty as 'when a lack of certainty of future climate threats is not seen as limiting to feeling and being secure' and unsafe certainty as 'when certainty (in terms of individuals' understanding of how the climate will change) puts them in a situation of potential harm'.
}

dynamic, complex social-ecological contexts (Armitage et al. 2009). The acknowledgement of the benefit of pluralism in the process of determining pathways makes explicit the need to consider multiple sources of knowledge, values, rules and norms (Fazey et al. 2016).

The IPCC and climate science in general presents a set of discourses around the issue of climate knowledge and uncertainty. In this article, we use keywords such as (un)safety and (un)certainty to analyse collective descriptions made around climate change adaptation by people in Senegal. In doing so, we introduce a pathway approach that recognises the inherent subjectivity ${ }^{3}$ of climate knowledge and attempts to harness sustainable routes towards climate adaptation (see Armitage et al. 2009). In the following text, we purposefully blur the distinctions between climate change and variability, seeing societal responses to contemporary climate information and forecasts as a route for adapting to longer term climate change while recognising that climate change might be sudden, irreversible and beyond what is experienced in terms of variability.

\section{Climate adaptation and uncertainty}

The issue of uncertainty lies at the very heart of climate, if not of all predictive science. At the most fundamental level, shedding light on scientific unknowns is a driving rationale for all scientific research. Indeed, a lack of certainty may be thought of as extending to the very basis of science in that theories in science can only be falsified rather than proved. Within atmospheric sciences, chaos, and by extension uncertainty, are fundamental characteristics of how the atmosphere varies and changes over time. Here, chaos means that even the smallest perturbations to the atmosphere can exert large impacts on how the atmosphere evolves over time. First shown by Edward Lorenz, the atmosphere's chaotic nature means that all forecasts of weather and climate must be treated as probabilistic and so contain some degree of uncertainty (Slingo and Palmer 2010).

Uncertainties in forecasts also arise from a lack of understanding of atmospheric processes and how they are represented by forecasting systems. Forecasting systems can be process based, statistically based or a mixture of both. Statistical-based forecasting systems in general use regression-based equations to represent the large-scale linkages between drivers of the atmosphere, such as sea surface temperatures and the state of the atmosphere. Whereas process-based models attempt to numerically account for processes explicitly, at a smaller

\footnotetext{
${ }^{3}$ In this article, we follow Morales and Harris (2014) definition of subjectivity as 'how one understands oneself within a social context—one's sense of what it means and feels like to exist within a specific place, time, or set of relationships' Morales and Harris (2014: 706).
} 
scale, either from first principles and/or by the means of parametrizations. Process-based dynamical models try to account for the chaotic nature of the atmosphere by performing multiple simulations with small random perturbations applied to the initial conditions of the simulations.

When we move to forecasting the atmosphere at longer time scales, the uncertainty of the dynamics of the atmosphere from chaos is added to by uncertainties in our understanding of other components of the climate system, such as how the ocean, biosphere, cryosphere, lithosphere and the sun, change and interact with each other and the atmosphere. For example, predicting patterns of volcanic activity, which can cause the rapid cooling of the planet, is severely limited to lead times of days to weeks. Uncertainty also arises from not knowing how the composition of the atmosphere in the future will change, with different societal pathways giving rise to different emissions and hence atmospheric concentrations of greenhouse gases and aerosols. Uncertainty in climate projections is further magnified when science tries to examine the impact that future climate changes will have on socio-ecological systems. This scientific perspective on climate change uncertainty has been nicely summarised in the work of Wilby and Dessai (2009) as the 'cascade of uncertainty'. Three other sources of uncertainty however add to this cascade: namely, uncertainty over which adaptation responses are chosen to deal with climate impacts, uncertainty around how effective these actions will be in mediating these impacts, and possibly most importantly, how other drivers of change, such as globalisation and population change will interact with climate change. This last source of uncertainty is potentially large and unpredictable. For example, agent-based simulations of how migration flows might evolve with climate change in West Africa showed emergent behaviour when population growth was also incorporated as a driver of demographic change (Kniveton et al. 2012).

While the uncertainty of forecasts as pertaining to inaccuracies in predicting the evolution of the atmosphere over time have been widely explored, less attention, particularly in terms of the use of climate information, has been focused on other dimensions of uncertainty. Specifically authors such as MacKenzie (1990), Van der Sluijs (1997, 2002, 2005, 2006) and Stirling (2001) have highlighted that uncertainty is at least partly socially constructed. This assessment always involves subjective judgement and value-based assumptions and thus, uncertainty should be assessed qualitatively as well as quantitatively. The social construction of uncertainty of science is of particular importance when looking at how science is used to make decisions. As highlighted by Van der Sluijs (2006: 72 ), the construction of uncertainty can be viewed as 'the product of implicit negotiation processes between scientists, policy-makers and the public'.

Decision-making, in the face of unquantifiable uncertainty in predicting the impacts of future climate, has highlighted the use of decision-based heuristics in determining adaptation efforts. These include 'flexiblity', so that adaptation efforts can change as new knowledge emerges, 'robustness', as in adaptation actions work over a range of climate scenarios, and of 'low-regrets', in terms of what is done today is not regretted in the future (Ranger et al. 2013; Haasnoot et al. 2013; Wise et al. 2014). How people deal with day to day uncertainty, such as when to plant seeds or when to harvest crops, is highly uncertain and collectively bound. Equally, ideas around what is considered an appropriate or safe decision in the face of climate risks is subjective. For example, in the arena of early warning systems around cyclones, it has been shown that in some social and cultural contexts, even though a functional early warning system is in place, the decision to not evacuate to shelters can still be prevalent among certain sections of a society. People, for example, explain remaining at home although having received warning messages of an approaching cyclone, due to religious beliefs (Ayeb-Karlsson et al. 2016, 2019). This example adds to a widely acknowledged notion that the barriers or limits to adaptation can be social and cultural (Adger and Vincent 2005; Adger et al. 2009; Nielsen and Reenberg 2010). In this sense, attitudes and knowledge towards risk and uncertainty becomes critical when trying to understand why some people manage to adapt while others do not (Oliver-Smith 1996; Wisner et al. 2004; Dessai and Hulme 2004). It is however important to acknowledge that culture, values and religious beliefs do not simply restrict and create barriers or limits to adaptation. Cultural values and attitudes rather inform whether people want to adapt, how they want to adapt, what is worth saving, and what is worth losing. In this way, analysing people's attitudes and values is an effective way to better understand what adaptation means to them. It is also important to think of cultural values and religion as potential tools for increased disaster preparedness or adaptive capacity. This is for example the case, when sacred buildings are used as cyclone and flood shelters, or when influential religious leaders take part in disaster relief and preparedness programs (Cheema et al. 2014; McGeehan and Baker 2017; Ayeb-Karlsson et al. 2019).

\section{A discursive framework to elaborate around climate uncertainty in Senegal}

Language and text are core fundaments that give meaning, value and understanding to our social lives and realities. In this way, they can effectively be analysed to detect changes and transformations in collectively shared beliefs, attitudes and perceptions. As people are social actors, they have the power to influence language and establish relationships between words, meanings and values through repeated communication (Foucault 1972, 1981; Fairclough 2003). Key mediums of social interaction are spoken and written words. An 
Fig. 1 Illustration of the conceptual model of safe uncertainty, adopted from Mason (1993: 195), and exemplifies positions of (un)safe (un)certainty
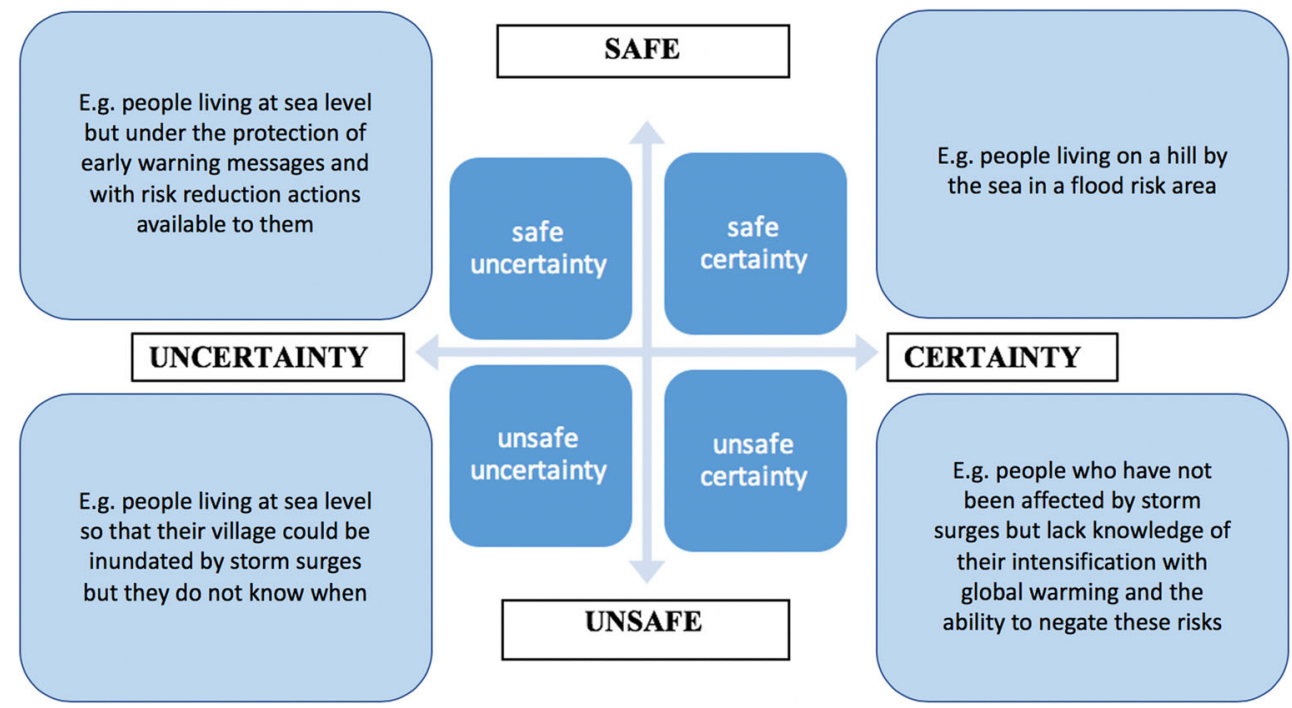

effective way of understanding shared storylines is therefore through the analysis of discourse (Foucault 1981; Fairclough 2003). Discourses can be thought of as collective spaces in which people communicate and act according to a common understanding of collective norms. In other words, they create and establish knowledge regimes within a social space. People position themselves and their identity within these collectively shared spaces. In doing so, they represent a perceived and interlinked subjective reality that is constantly transformed through social interactions (Foucault 1972, 1981; Fairclough 2003; Ayeb-Karlsson et al. 2018). Climate adaptation can through this lens be understood as a social process within this socio-political space (Eriksen and Lind 2009; Eriksen et al. 2015). The discourse lens within this article will help reveal the multi-level connections influencing people's decisionmaking and the power hierarchies in our Senegalese study area. This is because discourses - linked to power and knowledge - embrace particular combinations of words, narratives and practices that therefore result in specific social actions (Adger et al. 2001; Peet and Watts 2002; Meunier and Crane 2018). In this article, we will not attempt to detect or to identify competing or cooperative discourses, nor carry out any in-depth critical discourse analysis. Instead, we explore the discursive meanings and values around a few key concepts among agricultural stakeholders in Senegal.

The inter-discursive analysis was conducted in the following way: (1) we chose to introduce the key concepts of climate change, (un)certainty and (un)safety through a model of safe uncertainty (see Fig. 1) within individual interviews and group sessions; (2) we then analysed the way these concepts were described or given value and meaning inter-discursively or through the repeated semantic, grammatical and vocabulary relationships (see Fairclough 2003 or Ayeb-Karlsson et al. 2018 for a similar approach). In this inter-discursive analysis, we realised that much of the discussions and descriptions were aligned around the idea of knowledge and power. We also noticed that the framing around (un)certainty and (un)safety was binary structured. ${ }^{4}$

As explained, discourses - including power and knowledge interactions - regulate people's adaptive behaviour. These knowledge regimes refrain people from accidentally or intentionally stepping outside of the collectively established social norm. The communicative repetition through spoken and written language serves as a reminder of what people should think and how to behave. The qualitative dataset from Senegal with agricultural stakeholders therefore supports our understanding of their perceptions and attitudes around climate variability and change, impacts and adaptation.

To give an example, imagine the case of people dealing with climatic hazards such as cyclone strikes. Some people may consider evacuating to the shelter after receiving the warning message. However, this may not feel like a pathway towards certainty or safety for all. It is one adaptive pathway for some to deal with the environmental stress, but it does not necessarily work for all. A young unmarried woman for example, may not find safety in evacuating to the shelter. Perhaps she decides not to evacuate to a public shelter because this is seen as an 'inappropriate space' for a young unmarried woman. In this way, it is the social power relations in place within this discourse that refrain her from evacuating. In some parts of the world, such as in some areas of Bangladesh, a woman's place is at home, she is safe at home, and she should therefore not necessarily leave the house even though a climatic hazard is approaching (Begum 1993; Alam and Rahman

\footnotetext{
${ }^{4}$ Certainty and safety were described as positive, stable, productive and good, while uncertainty and unsafety were negative, risky, destructive and bad. This dual structuring is sometimes referred to as binary opposites, e.g. white and black, good and bad or feminine and masculine. It builds upon the idea that people feel a 'natural' need to order their reality this way to be able to feel like they understand the world (Foucault 2000, 2002).
} 
2014; Ayeb-Karlsson et al. 2016). As an unmarried woman, her mind prioritises the knowledge that suggests that if she gets sexually assaulted in the shelter, on the way to the shelter, or even is thought by others to have been assaulted, she may never marry. Instead, she would become an economic 'burden' to her family. She feels safer trying to survive the cyclone at home, than by putting her 'social status' at risk in the shelter. Knowledge, within a discourse, could act constraining or trapping someone into a seemingly (from another perspective) vulnerable position. Knowledge also determines what people consider as unsafe and uncertain.

The empirical data analysed was gathered in Senegal ${ }^{5}$ through 23 in-depth interviews and eight Focus Group Discussions (FGDs) with about 10-15 snowball sampled participants in each (see Table 1). The research sessions were all conducted in 2016 by local French-speaking researchers that were accompanied by the authors. The sessions were audio recorded, transcribed and translated into English. Observations and notes were also taken throughout sessions that included interactions between people in the group sessions. The interviewing and group sessions were all carried out around the topic of climate variability and change, impacts and adaptation, (un)safety and (un)certainty (see model in Fig. 1). The research sessions were conducted with regional agricultural stakeholders (including farmers, scientists and policymakers). All the participants represented an agricultural organisation in one way or another. Some of them were farmers on the side, others are farmers involved in policy or research (see Table 1). In this way, the participants were socio-economically fairly well off, although they had been through different levels of financial loss due to the climatic stressors. A few participants were women, although a vast majority of them were men. No group sessions were carried out with women only, yet in some groups, women attended and engaged in the conversations. The participants were all within the age of 20 to 69 . The respondents were selected through a form of snowball sampling based on the AMMA-2050 projects' institutional contacts. Further research would be required to engage with those more marginalised - where we envisage we would receive a more polarised response.

Similar theoretical frameworks (of discourse, power and knowledge) have been used to show how identity, space and subjectivities enable or constrain people's ability to adapt in Kenya and Senegal (Eriksen and Lind 2009; Eriksen et al. 2015; Meunier and Crane 2018). These studies illustrate how

\footnotetext{
$\overline{5}$ This case study was carried out in Senegal's Peanut Basin. French colonialist first introduced peanut plantations here in the nineteenth century, and the West African country has since then become one of the world's largest producers. Around half of Senegal's cultivated land is dedicated to peanut which has resulted in soil degradation, erosion and lack of vital nutrients. Other agricultural products grown in the area include millet, cowpeas, sorghum, okra and tomatoes. The area has recently experienced significant climate-related shocks, including drought, wind storms, flooding rain and unseasonable temperature changes.
}

Table 1 Overview of the informant's socioeconomic background including gender, occupation and age

$$
\begin{aligned}
& \text { Individual } \\
& \text { respondents } \\
& \text { Gender }
\end{aligned}
$$$$
\text { Occupation }
$$$$
\text { Technical ad }
$$$$
\text { Technical advisers } \quad 14 \quad 2
$$$$
\text { Policy-makers }
$$$$
\text { Farmers }
$$$$
\text { (dual roles) }
$$$$
\text { Age }
$$$$
20-29
$$$$
\text { 30-39 }
$$$$
40-49
$$$$
50-59
$$$$
\text { 60-69 }
$$

Group respondents

Gender

Occupation

Technical advisers

Policy-makers

Farmers (dual roles)

Other

Age

20-29

30-39

$40-49$

$50-59$

$60-69$

Note that some of the informants carry out dual occupations, such as farmers also involved in drafting and transforming localor regional policy legislations

people's behaviour, including their adaptive responses to climatic stress and shocks, are influenced by the social power relations and knowledge within the adaptive space. In this conception, adaptation strategies are viewed as socio-political processes that reveal how individuals and collectives interrelate with one another as well as with the environmental and social changes or disruptions. In line with this view, we argue that there is a need to reframe adaptation policy, practices and analysis to involve local and alternative adaptation knowledge. Furthermore, we argue that the inclusion of local knowledge and meaning enable societies to respond more effectively to socially created problems and vulnerabilities. We feel that people's perceptions of uncertainty are bound up with the dynamic outcomes and situations in which uncertainty is expressed. We particularly posit the idea that different understandings of climate knowledge can position people along a continuum of whether the use of this knowledge allows them to be safe, 
unsafe or in a position in between the two. In every day parlance, the terms certainty and safety are often considered closely related or even equivalent terms. We however take as a starting point the possibility that these characteristics are distinct even orthogonal to each other. This is why we use a conceptualisation of a decision-behaviour space that is contained within the axes from certainty to uncertainty and unsafety to safety (see Fig. 1 adopted from Mason (1993: 195) where the spectrum of certainty to uncertainty pertains to knowledge of climate risks, and that of unsafe to safe is associated with how one sees one's livelihood or outcome of a decision.

The conceptual model of safe uncertainty ${ }^{6}$ is used widely in the discipline of family therapy to manage problems, risk and change (Mason 1993; Vivian-Byrne 2001). The conceptual framework aligns well with our research problem as it represents a way of moving away from certainty and the idea that solutions will solve all things (Mason 1993: 194). In the sphere of therapy, the space of safe uncertainty is seen as the most therapeutic or a more 'reasonable' emotional state as it allows new explanations to emerge alongside the current context rather than the new information competing with a fixed or nontransformative psychological position (Mason 1993; VivianByrne 2001). Likewise, in a changing climate, we characterise the safe uncertainty space as one which promotes dialogue and learning through the contribution of different stakeholder's views with varying knowledge and purposes to form different pathways to adaptation which are flexible, robust and lowregrets (Ranger et al. 2013). In this article, we posit that movements within the larger space of uncertainty to certainty and unsafety to safety requires a recognition of the role of knowledge and power. Uncertainty does not preclude safety, and understanding someone's position in this space benefits from different perspectives/sources of knowledge through dialogue. Clearly, key to this conception is the recognition of the subjective element of what is considered certain and uncertain, or safe and unsafe. For example, one person living in an urban hotspot may define someone-else's living condition in a climatic highrisk rural area as highly unsafe or uncertain. However, that very same person may point out that it is much safer to live in a rural village than within the urban dangers of a city.

This article will therefore apply the conceptual keywords of climate change, (un)safety, and (un)certainty to understand different pathways of adaptation in Senegal. In doing so, it highlights the idea of safe uncertainty being accepting of uncertainty

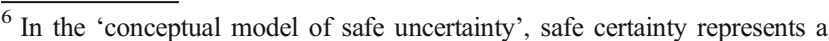
utopic state, or an unachievable emotional or psychological position as one never can be completely certain that they are totally safe. In the area of therapy, certainty represents the knowing about the condition to be threated while the movement represents the work of the therapist to move the client towards a 'better place'. The term safety here refers to containment and protection of the client, public and staff throughout the movement. In other words, clients will generally seek help from a position of unsafe uncertainty or unsafe certainty while believing that the therapist will be able to offer them a position of safe certainty (Vivian-Byrne 2001: 109).
}

and not limiting. This while also acknowledging that power and knowledge influence the position of someone, a society or an institution within a collective adaptive space, or discursive values of how to move (pathways to adaptation) from one psycho-emotional space to another in the face of climate risks.

\section{Climate uncertainty and adaptive pathways in Senegal}

Rainfall variability in West Africa over recent decades has been among the most extreme in the world. The drought that started at the end of the 1960s is now recognised as one of the strongest climatic signals since meteorological measurements began (Hulme et al. 2001). The high vulnerability of many in the region has meant that past climate extremes have led to high losses in lives and livelihoods resulting in the impoverishment and displacement of many. Since the droughts of the 1970s and 1980s, while there has been a partial recovery of the rains, many urban areas now suffer from an increase in severe flooding.

While there is a solid physical understanding of the causes of historical climate variability in the region, there is a large amount of uncertainty in predicting climate variability at seasonal and longer timescales. Currently, there is no consensus on how changes in greenhouse gases, land cover and aerosols will impact future rainfall, in terms of the seasonal total and its distribution within the wet season. Importantly, in terms of societal impact, there is limited knowledge of how highimpact weather (HIW) events may change in the near and long-term future. This uncertainty, coupled with a weak capability to plan investments on varying timescales, results in a paucity of climate knowledge being used as a guide to development decision-making.

\section{Applying the conceptual model of safe uncertainty to climatic risks in Senegal}

In this context, the multi-institutional African Monsoon Multidisciplinary Analysis, AMMA-2050 project aims: (1) to provide expert judgement on future projections of HIW; (2) to create tools and methodologies for using these projections for planning within the agricultural and hydrological sectors, and (3) to demonstrate the potential for effective application of reliable 5-40-year climate projections and associated uncertainties in regional to local scale decision-making. One of the focuses of AMMA-2050 is building the resilience of agriculture to climate change. Based in Senegal, the relevant pilot study in the project aims to establish a planning and policy framework which bridges the knowledge gap between climate scientists and the agricultural planning processes. Involving agricultural key actors (farmers, scientists, policymakers), the project has documented and is trialling existing 
and new climate resilient agricultural practices, including collaborative cultivar breeding strategies, with the potential to increase adaptive capacity in the study area that might be up-scaled to other parts of West Africa.

The following results come from some of the research sessions held with stakeholders from southern and central Senegal. These areas experience a Sudano-Sahelian climate, characterised by high temperatures $\left(28.1^{\circ} \mathrm{C}\right.$ for $\left.1980-2013\right)$ and low rainfall (474 $\mathrm{mm}$ for 1980-2013), with the wet season occurring between mid-June and mid-September (Salack et al. 2011). The area is characterised by a high level of naturally saline soil and salinized soil due to land degradation (17\% of the total land, see Diome 2015). To adapt to high inter-annual variability of rainfall, farmers in this area had developed low risks strategies (low inputs and low but stable yields) that have placed them in what some might consider a position of safe uncertainty. However, in the context of climate change with fears of increasing variability and extreme weather combined with a desire for improved food security and livelihoods, farmers of the Peanut Basin are starting to feel, more frequently, in an unsafe and uncertain space.

To initiate a discussion, the conceptual model of safe uncertainty (shown in Fig. 1) was drawn and its function explained to the participants. The authors acknowledged that there was a potential risk of influencing the participants' perceptions around the key concepts of (un)safety and (un)certainty through the examples used to illustrate the model. The way the researches dealt with this was by:

(1) Using unfamiliar environmental stressors. The hazards used in these examples, tropical cyclones, do not exist to a large extent in this region. People here are mainly dealing with droughts and dry spells.

(2) The conceptual choice of methodology. This study aimed to capture the discursive meanings and values around these concepts. In doing so, the researchers introduced these concepts within an open-ended interview or group discussion, but allowed people themselves to elaborate, give meaning and deeper describe the sociocultural values around the concepts.

To illustrate the function of the model, hypothetical examples of people in the four positions were given:

a. Safe certainty was illustrated by people living on a hill by the sea in a flood risk area.

b. Unsafe uncertainty was portrayed by people living at sea level meaning that the village would be inundated by storm surges, but they did not know when it might occur.

c. Unsafe certainty was described as people who presently had never been affected by storm surges, while lacking knowledge of sea level rise, an intensification of cyclones with global warming, and the ability to negate these risks. d. Safe uncertainty was ultimately explained as people living at sea level, but under the protection of early warning messages notifying them of the approaching storm surges and with risk reduction actions available to them.

After explaining the model, the participants were asked to elaborate and debate around their places and situations. They were also consulted on how they saw themselves and their reality fitting into the four positions. These elaborations related to the climate risks that they currently faced, as well as potential future climate impacts on their livelihoods. The participants were also asked what changes they envisage that could help them to move within the four position in the model.

\section{Results from the safe uncertainty sessions in Senegal}

The rest of this section will present the results of the research sessions. According to some participants, salinization of soil and extreme events were seen as placing them in an unsafe certainty space as extreme events always happen and salinization has always existed. To move from a situation of suffering due to these issues to a safe certainty space, the participants highlighted the use of a local development plan that restricts the use of the salinized land. However, several participants expressed how such a move towards safety and greater certainty, while desirable, may not be that easy to realise. Some even referred to it being a 'dream'.

Financial capital was referred to as a limiting factor in the move towards safer certainty. For example, drought- and flood-resistant crops may ensure a greater degree of certainty, but these seeds are more expensive and yields can be low.

The problems of food shortages mean that we have very little to invest when we need to think of how to deal with dryer or wetter conditions. /.../ The special seeds are very expensive.

One of the most important ways to reach a safer place was said to be through 'better communication' of 'information' or 'knowledge'. However, the participants sometimes felt that information was kept from them by the government representatives for their benefit. In this way, the issue of climate change ended up playing an important role in the power dynamics between key actors within the government. As a result, policy was seen as a constraining factor of pathways to adaptation. This was because the respondents felt as policy was being used as a tool against them to control the people, and to increase the benefits for those already in power. In such instances, people explained feeling locked into unsafe places, or positions with limited adaptation pathway options:

Land [earmarked by the government] for development, that we could use, has not been touched for years. We 
are not even allowed to graze our cattle there. To arrive at a safe position even with uncertainty is... [another participant interrupts]. A dream, these are dreams. I suppose we must as a starting point prioritise how we mobilise [change in speaker].

Improving communication is the best way of making changes that are effective, only then can we move to a safer place. Though the information is used by government representatives for themselves.

Climate change is transforming the political landscape. We see departments who should be working together, because of the changes taking place, still not communicating. Everyone involved is finding their own position.

In terms of why people remain in unsafe uncertainty, respondents cited the lack of forecasts of the wet season onset and end dates, the post-wet season rain spells, the occurrence of long dry spells, strong wind events and the rainfall distribution during the wet season, as increasing agricultural livelihood vulnerability. Pathways to move to a safe uncertainty space included better climate information (knowledge), the establishment of windbreaks (including the planting of trees and the development of agroforestry), the adoption of water retention technology such as Zai pits and encouraging plant diversity:

To arrive at a position of greater safety and certainty as in the box, we need a good strategy for water resource management, a good way of how to deal with climate information, options on the right varieties [of plants], more information on how to deal with soil conditions, transfer of technologies, improved techniques for adaptation and the restoration of ecosystems. Nevertheless, we still face obstacles including the implications of de-population, lack of available human resources, and financial constraints. There are also issues with the lack of coordination between NGOs /.../ For many years they [naming the National Government Agencies] provided lots of information but it is badly used.

Next to technological and financial resources (resources secured through altered power relations), people pointed out that there was a need for knowledge of how to strategically deal with climate information. The dissemination of climate information was not seen as enough, without the knowledge about how to use the information. Suspicion existed that the knowledge on how to use climate information was being withheld by government officials which presented a barrier to the movement of people to a safer space:

The Meteo [Government Weather Service] rarely give us information and when they do it is hard to use.
When pushed further on the reasons why information was seen as irrelevant and difficult to use, many suggested that the information did not give a complete picture from which they could make decisions. In these instances, they relied on traditional knowledge to take decisions. The traditional knowledge was mostly available to them, even when the meteorological information was absent.

It was also suggested that to move from a situation of unsafe uncertainty to one of safe certainty, households, or members of households, could migrate. The ensuing discussion from this suggestion included whether such migration might however in certain situations lead to people finding themselves in unsafe certainty. This was because households, for example, relocated to slum areas that were prone to urban flash flooding, or that while reducing climate vulnerability suffering further economic vulnerability. Participants also highlighted that migration could perhaps move part of a household towards greater safety, but position those who are left behind, especially women, in deeper unsafe uncertainty:

We need alternative thinking, or for the local NGOs to prepare people to leave the countryside and move to the city by providing training in non-agricultural activities. There is an expectation for those that leave to contribute financially to the family back home, and they find it extremely hard to survive in the city.

One individual generally takes key decisions. These decisions are often very socio-cultural. The erosion of the family because of food insecurity - such as the migration to the cities - can really create problems particularly for women.

The approach outlined above provides a fertile landscape to start the process of identifying discursive pathways of, and barriers to, adaptation to climate variability and change as envisaged by local stakeholders in Senegal. In this conception, the two dimensional conceptual space of safety and certainty is influenced by the third dimension, power. Power plays a significant role in shaping the direction of discursive adaptive pathways. The participants gave a host of reasons why they and most of their peers occupied an uncomfortable space of unsafe uncertainty and unsafe certainty. Interestingly, the certainties that they identified were issues that many saw beyond or outside of their control:

Many problems that relate to climate we have no control over. People from the town used to come to us farmers to buy produce but our yields have gotten smaller and our prices have gone up. They now go to the town for their things.

Access to knowledge was also identified as being beyond the participant's control. Some farmers, for example, explained 
the inability to move towards safe certainty by not having direct access to climate information or knowledge. Many still relied on indigenous knowledge, caught in a space of uncertainty because of conflicting information.

We never talk to the people giving us the information. We get the information and have to decide what to do. Too many people tell us different things.

Climate information is provided as only weather [forecasts at daily timescales] as this is what the authorities believe local farmers need.

The information we receive is never specific enough to our sector.

The participants, also pointed out that decision-makers, such as regional government agencies, have direct access to knowledge. Among 'regular people', those with greater social capital, due to age or experience, were also better able to access knowledge:

What we need from the decision-makers is for the [climate] information to be more precise. We must also adapt its usage to need.

We need to look at old methods to see what works because we do not have the skills or expertise to do what is needed. The Regional Government Agency understands the importance of giving the information to us producers but we need to know what to do with it.

The Elders suggested that their fathers and grandfathers knew well how to increase their adaptive capacity. Some people find adaptation much easier only because their grandfathers passed this knowledge along to them. At a local level, some farmers were therefore able to detect, integrate and respond to climate variability quicker than others.

The participants identified social norms and power relations as principle factors locking people into an uncertain and unsafe space. For example, it was mentioned that people reproduce the behaviour of their families and villages even though it may be maladaptive. According to the participants, farmers tend to mistrust or take great 'caution' before trusting other members of the society which can act as a block to the transfer of new knowledge:

There is a problem with everyone doing different things to deal with the changing seasons and climate. The way everyone acts is based on how their families and communities act. This means that people do not always work together or really have power to buy the seeds they think they might need.

Trust is critical in the thinking of farmers so not wanting to ruin this is very important. Farmers are very perceptive as part of their role and as such approach all things with caution. Change is difficult and economics impact or compounds on their thinking.

The participants also introduced another interesting element in their description of knowledge. To adopt an adaptive pathway, and move towards safe certainty, some participants explained that they do not need climate information but knowledge relevant to themselves. Some respondents described how the competition between traditional and technological knowledge confused them. In this way, traditional knowledge was reinforced as less valued than technological knowledge:

Sometimes the government tells us things that go against our indigenous knowledge. What are we supposed to do? We have to do what is best for our families.

As observed, the descriptions around how to move towards greater certainty and safety were strongly influenced by sociocultural values and meanings around knowledge. Even though financial capital was mentioned as a potential limitation to reach greater safety and certainty, knowledge, and the feeling of being at ease with the decisions made, was more important. If people felt that they had obtained the traditional knowledge to predict a dry spell or drought, they would simply choose not to farm, plant drought-resistant seeds, or migrate away temporarily to a place where they could tend to another livelihood activity. This is interesting, as it illustrates that most and foremost it was people's perceptions around what is safe and how one can be certain that drove their adaptive responses.

\section{Discussion}

This article outlines the development and use of a theoretical framework encompassing themes of uncertainty and safety to open up the discussion of pathways to adaptation to the impacts of climate change (Mason 1993; Haasnoot et al. 2013; Fazey et al. 2016). The Senegalese case study used to illustrate the approach revealed a variety of perceptions in relation to climate hazards, (un)certainty and (un)safety. People pointed out that to be able to adapt, and move from unsafe positions, the existence of climate information is not enough, while implicitly acknowledging the role of information and knowledge in adaptation. Access to climate information, or the knowledge of how to obtain climate information, equals power and can allow people to move towards greater safety. 
The participants described different ways that knowledge was un-accessible or being kept from them. It was expressed that those with power sometimes kept the knowledge to themselves deliberately for their benefit, and to protect their power positions. This was, for example, illustrated by the elderly participants who claimed that former generations used to know very well how to adapt to the observed climatic changes. This indigenous knowledge was being passed along to their children which made people more resilient to the changes. However, at the same time, a few participants expressed how they found it confusing that the meteorological climate information and indigenous traditions seemed to be clashing.

This narrative potentially illustrates a transformative shift in the climate adaptation discourse. It is clear that there is a need for more, or rather 'better', climate information and knowledge. This includes climate data at seasonal and long-term scales, in order to adapt to the problems presented to people by climate hazards, but critical local consultations and need assessments also ought to be carried out (Wise et al. 2014; Ayeb-Karlsson et al. 2016; McGeehan and Baker 2017). The ideas presented in this article aim to open up a critical discussion of how we perceive uncertainty and how it is framed. Currently, uncertainty is continuously framed as something we need to avoid, minimise and work against. This is particularly evident and well documented among the science community (Jasanoff et al. 1998; Keeley and Scoones 2014). In contrast, we posit the idea that uncertainty in climate knowledge is not only essential to adaptation, but it is something that broadens the discussion of alternative knowledge and pathways for adaptation. This is evidently not a new panacea. As a tool for survival, we need to be able to respond to change quickly. Uncertainty, can be thought of as the fuel for this trait (Adger and Vincent 2005; Van der Sluijs 2006). We argue for embracing uncertainty as it may provide constructive solutions for vulnerable people living under climate uncertainty.

Interestingly, some respondents in this Senegalese study suggested that it would be impossible to arrive at a safe and certain space. According to the participants, the continuum of time with this inherent uncertainty always leaves the door open to another unsafe possibility emerging. When applied to the model of safe uncertainty, we can envisage that while adaptation can move somebody towards a position of greater safety, the model will also shift with them because of future uncertainty in terms of climate, policy and societal changes. In the same way that safe certainty represents a utopic (and unreachable) state that people aim for within family therapy (Mason 1993; Vivian-Byrne 2001), people here acknowledged and expressed similar feelings in the context of climate change adaptation. This resulted in placing people in a space of further worries, where they found a need to keep adapting short-term over and over again.

This flux and constant need to adapt is one explanation of why uncertainty should not be viewed as constraining, but in fact enabling by opening up multiple pathways of change. People's cultural values, reality or knowledge in Senegal, just like anywhere else, can be understood as normatively disguised through social and dynamic repetition. When a person moves from what they feel is an unsafe position to a safe space, the decision is based on the values, norms and beliefs reproduced within the social discourse. This is also why people do not necessarily describe their home or living situation as unsafe. People's perceptions around their reality rules their actions and behaviours. These beliefs, or perceptions, can determine if someone migrates away from climatic stress, or decides to plant drought-resistant crops this year (Foucault 2002; Nielsen and Reenberg 2010; Meunier and Crane 2018). In other words, discursive values play an important role in how people respond to the impact and uncertainty of an upcoming drought. As this study has shown, most people operate in the grey of uncertainty for many aspects of their lives - what to grow, when to plant, when to harvest. In most cases, people's decisions and actions are not based on climate information, but on social reproduction and emotions of what feels right to them.

\section{Conclusion}

Uncertainty is an inherent characteristic of climate variability and change, and the impacts they have on the world. At the same time, the climate knowledge used to cope with climate hazards comes from a variety of sources including science, experience, traditions, socio-cultural norms, observing nature and beyond. Understanding and using climate information is conditioned by subjectivities and capabilities. This article has explored people's positions, in terms of climate risks and pathways to adaptation through the analytical use of keywords such as knowledge, power, (un)safety and (un)certainty.

Acknowledgements We are grateful for the valuable contribution of Laure Tall at Institut Sénégalais de Recherches Agricoles in Senegal. We also thank the reviewers and editors at Regional Environmental Change, and our colleagues at University of Sussex, IDS and UNUEHS for their generous support, advice and guidance leading up to the publication of this manuscript.

Funding information This research was partly funded by the Natural Environmental Research Council (NERC) and Department for International Development (DFID) under the Future Climate for Africa (FCFA) programme (NE/M02024X/1). For the sake of transparency, it should be noted that several authors are involved and receive funding from the AMMA-2050 project (NEC05274).

Open Access This article is distributed under the terms of the Creative Commons Attribution 4.0 International License (http:// creativecommons.org/licenses/by/4.0/), which permits unrestricted use, distribution, and reproduction in any medium, provided you give appropriate credit to the original author(s) and the source, provide a link to the Creative Commons license, and indicate if changes were made. 


\section{References}

Adger WN, Vincent K (2005) Uncertainty in adaptive capacity. Compt Rendus Geosci 337(4):399-410. https://doi.org/10.1016/j.crte.2004. 11.004

Adger WN, Benjaminsen TA, Brown K, Svarstad H (2001) Advancing a political ecology of global environmental discourses. Dev Chang 32:681-715. https://doi.org/10.1111/1467-7660.00222

Adger WN, Dessai S, Goulden M, Hulme M, Lorenzoni I, Nelson DR, Naess LO, Wolf J, Wreford A (2009) Are there social limits to adaptation to climate change? Clim Chang 93(3-4):335-354. https://doi.org/10.1007/s10584-008-9520-z

Alam K, Rahman MH (2014) Women in natural disasters: a case study from southern coastal region of Bangladesh. Int J Disaster Risk Reduct 8:68-82. https://doi.org/10.1016/j.ijdrr.2014.01.003

Armitage DR, Plummer R, Berkes F, Arthur RI, Charles AT, DavidsonHunt IJ, Diduck AP, Doubleday NC, Johnson DS, Marschke M, McConney P (2009) Adaptive co-management for socialecological complexity. Front Ecol Environ 7(2):95-102. https:// doi.org/10.1890/070089

Ayeb-Karlsson S, van der Geest K, Ahmed I, Huq S, Warner K (2016) A people-centred perspective on climate change, environmental stress, and livelihood resilience in Bangladesh. Sustain Sci 11(4):1-16. https://doi.org/10.1007/s11625-016-0379-Z

Ayeb-Karlsson S, Smith CD, Kniveton D (2018) A discursive review of the textual use of 'trapped' in environmental migration studies: the conceptual birth and troubled teenage years of trapped populations. Ambio 47(5):557-573. https://doi.org/10.1007/s13280-017-1007-6

Ayeb-Karlsson S, Kniveton D, Cannon T, van der Geest K, Ahmed I, Derrington EM, Florano E, Opoiyo Opoyo D (2019) I wont go. I cannot go: cultural and social constraints to disaster preparedness in Asia, Africa and Oceania. Disasters (Forthcoming)

Baldwin A (2016) Pre-mediation and white affect: climate change and migration in critical perspective. Trans Inst Br Geogr 41(1):78-90. https://doi.org/10.1111/tran.12106

Begum R (1993) Women in environmental disasters: the 1991 cyclone in Bangladesh. Gend Dev 1(1):34-39. https://doi.org/10.1080/ 09682869308519953

Cheema AR, Scheyvens R, Glavovic B, Imran M (2014) Unnoticed but important: revealing the hidden contribution of community-based religious institution of the mosque in disasters. Nat Hazards 71: 2207-2229. https://doi.org/10.1007/s11069-013-1008-0

Dessai S, Hulme M (2004) Does climate adaptation policy need probabilities? Clim Pol 4:107-128. https://doi.org/10.1080/14693062. 2004.9685515

Diome F (2015) Impact of salinity on the physical soil properties in the groundnut basin of Senegal: case study of Ndiaffate. Int J Chem 7(2):198

Eriksen SH, Lind J (2009) Adaptation as a political process: adjusting to drought and conflict in Kenya's drylands. Environ Manag 43(5): 817-835. https://doi.org/10.1007/s00267-008-9189-0

Eriksen SH, Nightingale AJ, Eakin H (2015) Reframing adaptation: the political nature of climate change adaptation. Glob Environ Chang 35:523-533. https://doi.org/10.1016/j.gloenvcha.2015.09.014

Fairclough N (2003) Analysing discourse: textual analysis for social research. Routledge, London

Fazey I, Wise RM, Lyon C, Câmpeanu C, Moug P, Davies TE (2016) Past and future adaptation pathways. Clim Dev 8(1):26-44. https://doi. org/10.1080/17565529.2014.989192

Fischer AP (2018) Pathways of adaptation to external stressors in coastal natural-resource-dependent communities: implications for climate change. World Dev 108:235-248. https://doi.org/10.1016/j. worlddev.2017.12.007

Foucault M (1972) The archeology of knowledge. Routledge, London
Foucault M (1981) The order of discourse (I. McLeod, Trans.) untying the text: a post-structuralist reader. Routledge, London

Foucault M (2000) In: Rabinow P (ed) Ethics, subjectivity and truth: the essential works of Foucault 1954-1984, vol 1. Penguin Books, London

Foucault M (2002) The order of things: an archaeology of the human sciences. Routledge, London and New York

Haasnoot M, Kwakkel JH, Walker WE, ter Maat J (2013) Dynamic adaptive policy pathways: a method for crafting robust decisions for a deeply uncertain world. Glob Environ Chang 23(2):485-498. https://doi.org/10.1016/j.gloenvcha.2012.12.006

Hulme M (2010) Problems with making and governing global kinds of knowledge. Glob Environ Chang 20(4):558-564. https://doi.org/10. 1016/j.gloenvcha.2010.07.005

Hulme M (2011) Reducing the future to climate: a story of climate determinism and reductionism. Osiris 26(1):245-266. https://doi.org/10. $1086 / 661274$

Hulme M, Doherty R, Ngara T, New M, Lister D (2001) African climate change: 1900-2100. Clim Res 17(2):145-168. https://doi.org/10. $3354 / \mathrm{cr} 017145$

IPCC (2014) Summary for policymakers. In: climate change 2014: impacts, adaptation, and vulnerability. Part A: global and sectoral aspects. In: Field CB, Barros VR, Dokken DJ, Mach KJ, Mastrandrea MD, Bilir TE, Chatterjee M, Ebi KL, Estrada YO, Genova RC, Girma B, Kissel ES, Levy AN, MacCracken S, Mastrandrea PR, White LL (eds) Contribution of working group II to the fifth assessment report of the intergovernmental panel on climate change. Cambridge University Press, Cambridge, United Kingdom and New York, USA, pp 1-32

Jasanoff S, Wynne B, Buttel F, Charvolin F, Edwards P, Elzinga A, Haas P, Kwa C, Lambright WH, Lynch M (1998) Science and decisionmaking. In: Rayner S, Malone EL (eds) Human choice and climate change. Battelle Press, Ohio

Keeley J, Scoones I (2014) Understanding environmental policy processes: cases from Africa. Routledge, London

Kniveton DR, Smith CD, Black R (2012) Emerging migration flows in a changing climate in dryland Africa. Nat Clim Chang 2(6):444- 447. https://doi.org/10.1038/nclimate1447

MacKenzie D (1990) Inventing accuracy. MA, MIT Press, Cambridge

Mason B (1993) Towards positions of safe uncertainty. Hum Syst 4(3-4): 189-200

McGeehan KM, Baker CK (2017) Religious narratives and their implications for disaster risk reduction. Disasters 41:258-281. https://doi. org/10.1111/disa. 12200

Meunier J, Crane TA (2018) Pastoral adaptation and policy environment: how discourses shape knowledge, policy and adaptation. CCAFS working paper 225 CGIAR. CCAFS, Wageningen

Morales MC, Harris LM (2014) Using subjectivity and emotion to reconsider participatory natural resource management. World Dev 64: 703-712. https://doi.org/10.1016/j.worlddev.2014.06.032

Nielsen J, Reenberg A (2010) Cultural barriers to climate change adaptation: a case study from Northern Burkina Faso. Glob Environ Chang 20(1):142-152. https://doi.org/10.1016/j.gloenvcha.2009. 10.002

Oliver-Smith A (1996) Anthropological research on hazards and disasters. Annu Rev Anthropol 25:303-328. https://doi.org/10.1146/ annurev.anthro.25.1.303

Peet R, Watts M (2002) Liberation ecologies: environment, development and social movements. In: Routledge. London, New York

Ranger N, Reeder T, Lowe J (2013) Addressing 'deep' uncertainty over long-term climate in major infrastructure projects: four innovations of the Thames estuary 2100 project. EURO J Decis Process 1(3-4): 233-262. https://doi.org/10.1007/s40070-013-0014-5

Salack S, Muller B, Gaye AT (2011) Rain-based factors of high agricultural impacts over Senegal. Part I: integration of local to sub- 
regional trends and variability. Theor Appl Climatol 106(1-2):1-22. https://doi.org/10.1007/s00704-011-0414-z

Slingo J, Palmer T (2010) Uncertainty in weather and climate prediction. Philos Trans R Soc A Math Phys Eng Sci 369:4751-4767. https:// doi.org/10.1098/rsta.2011.0161

Stirling A (2001) Inclusive deliberation and scientific expertise: precaution, diversity and transparency in the governance of risk. In: PLA Notes 40. Deliberative democracy and citizen empowerment. IIED, London, pp 67-71

Taylor R, Butterfield RE, Bharwani S, Taylor A, Devisscher T (2017) Research methods for understanding and supporting decision processes in African cities. In: FRACTAL Working Paper 5 Stockholm Environment Institute. Oxford Centre, Oxford

Van der Sluijs JP (1997) Anchoring amid uncertainty: on the management of uncertainties in risk assessment of anthropogenic climate change. $\mathrm{PhD}$ thesis. Utrecht University, Utrecht, The Netherlands

Van der Sluijs JP (2002) A way out of the credibility crisis of models used in integrated environmental assessment. Futures 34:133-146. https://doi.org/10.1016/S0016-3287(01)00051-9

Van der Sluijs JP (2005) Uncertainty as a monster in the science policy interface: four coping strategies. Water Sci Technol 52(6):87-92. https://doi.org/10.2166/wst.2005.0155

Van der Sluijs JP (2006) Uncertainty, assumptions, and value commitments in the knowledge-base of complex environmental problems.
In: Pereira ÂG, Vaz SG, Tognetti S (eds) Interfaces between science and society. Routledge, London, pp 67-84. https://doi.org/10.4324/ 9781351280440

Vivian-Byrne SE (2001) What am I doing here? Safety, certainty and expertise in a secure unit. J Fam Ther 23:102-116. https://doi.org/ $10.1111 / 1467-6427.00171$

Wilby RL, Dessai S (2009) Robust adaptation to climate change. Weather 65(7):180-185. https://doi.org/10.1002/wea.543

Wilson GA (2014) Community resilience: path dependency, lock-in effects and transitional ruptures. J Environ Plan Manag 57(1):1-26. https://doi.org/10.1080/09640568.2012.741519

Wise RM, Fazey I, Stafford Smith M, Park SE, Eakin HC, Archer Van Garderen ERM, Campbell B (2014) Reconceptualising adaptation to climate change as part of pathways of change and response. Glob Environ Chang 28:325-336. https://doi.org/10.1016/j.gloenvcha. 2013.12.002

Wisner B, Blaikie P, Cannon T, Davis I (2004) At risk: natural hazards, people's vulnerability and disasters, Second edn. Routledge, London and New York

Publisher's note Springer Nature remains neutral with regard to jurisdictional claims in published maps and institutional affiliations. 